\title{
A reforma do ensino médio Suprime direitos, privatiza a educação e terceiriza os/as trabalhadores/as escolares
}

Medida Provisória n. 746, enviada pelo Executivo Federal ao Congresso em
22 de setembro de 2016, foi aprovada na forma da Lei n. 13.415, sancionada
em 16 de fevereiro de 2017. A proposta possui vício de origem, de forma e de conteúdo, por não se pautar no debate democrático e nas reivindicações sociais, e não atende aos requisitos de relevância e urgência requeridos pelo art. 62 da Constituição, razão pela qual a CNTE ingressou com ação direta de inconstitucionalidade (ADI) contra a MP, posteriormente convertida em Lei Federal, sendo que se mantém válida e pendente de julgamento.

A reforma do ensino médio no Brasil se situa em um conjunto mais amplo de medidas neoliberais e conservadoras, que caracterizam o governo do ilegítimo presidente Michel Temer, considerado golpista por grande parte da literatura jurídico-política e pelos movimentos sociais.

O golpe que apeou a presidenta Dilma Rousseff do poder se expressa de inúmeras formas. A principal delas diz respeito à mudança radical na agenda político-social, que tem contrariado o desejo de 54,5 milhões de eleitores que derrotaram nas urnas o projeto neoliberal.

Na educação, o eleitorado aprovou o avanço nas políticas públicas, sobretudo com acesso à universidade para as classes populares e com a universalização das matrículas com qualidade na escola pública de nível básico.

O Plano Nacional de Educação (PNE) constitui a referência para o projeto educacional do País na década que termina em 2024. O Sistema Nacional de Educação, o Custo Aluno Qualidade, o Piso Salarial e as Diretrizes Nacionais de Carreira para os profissionais da educação são políticas prioritárias do PNE. A meta 20 do Plano Decenal prevê atingir o investimento equivalente a $10 \%$ do PIB na educação, especialmente por meio das riquezas oriundas da camada Pré-sal de petróleo e gás natural, que, no entanto, já estão sendo privatizadas pelo governo atual.

A olho nu, a agenda do golpe se contrapõe às metas do PNE não apenas nas questões quantitativas. Querem interferir diretamente na formação dos estudantes, limitando o debate e o conteúdo dos currículos escolares - vide o projeto da Lei da Mordaça (Escola sem Partido), que caminha pari passu com a reforma do ensino médio.

Segundo dados da Pesquisa Nacional por Amostra de Domicílios (Pnad-2010), mais da metade da população com 25 anos de idade ou mais não concluíram o ensino 
fundamental. E quase metade da população entre 15 e 17 anos também não cursa o ensino médio, seja pela distorção idade-série que aprisiona os jovens no ensino fundamental - estimulando a evasão precoce da escola -, seja por motivos de inserção prematura no mundo do trabalho.

Em que pese a necessidade de voltar os objetivos do ensino médio para os excluídos do processo escolar - e a educação de jovens e adultos (EJA) conjugada à educação técnica profissional é a melhor alternativa para incluir na escola o grande contingente de jovens e adultos trabalhadores -, a reforma do ensino médio silencia sobre a oferta escolar no período noturno e sobre a própria EJA. Pior: a proposta inverte os objetivos, que deveriam focar o público adulto, direcionando aos jovens em idade escolar (15 a 17 anos) uma formação voltada somente à melhoria da nota no Índice de Desenvolvimento da Educação Básica (Ideb) - com prioridade de apenas duas disciplinas, Português e Matemática -, e com o agravante de impor às classes populares quase que exclusivamente a educação técnico-profissional, como parte específica do currículo, sendo esta a única alternativa à universidade, que ficará cada vez mais distante.

Diante desse contexto político, social e educacional, a CNTE considera a reforma do ensino médio ilegítima, antidemocrática, extemporânea, cerceadora de direitos e de base estritamente neoliberal. Em síntese, a reforma fomenta a privatização das escolas públicas, promove a terceirização da força de trabalho, principalmente do magistério, e rompe com as Diretrizes Curriculares Nacionais do Ensino Médio.

A reforma retira do currículo do ensino médio (público) as disciplinas de Sociologia e Filosofia, tornando-as optativas junto com a Língua Espanhola. Nada obsta, porém, que as escolas privadas mantenham essas disciplinas, visando um plus de conhecimento para sua clientela. Essa medida de ajuste curricular se alinha ao propósito de redução dos gastos públicos, pois serão menos professores para se formar em universidades e para contratar nos sistemas de ensino.

A mesma lógica economicista tornou obrigatórias nos três anos do ensino médio apenas as disciplinas de Português e Matemática, devendo as demais áreas de conhecimento ser ofertadas em menor tempo ou de forma intensiva.

Ainda sobre os profissionais da educação, lamentavelmente, o Congresso Nacional ampliou a desregulamentação da carreira dos/as educadores/as das redes públicas escolares, pretendida inicialmente pelo Executivo Federal. Além da possibilidade de serem contratados profissionais com "notório saber" para ministrar aulas na modalidade de educação técnica-profissional, foi incluído mais um segmento de "profissionais" no rol do art. 61 da LDB. Trata-se dos bacharéis que concluírem a complementação pedagógica aligeirada para atuar em todas as etapas e modalidades da educação básica - um enorme retrocesso frente à luta histórica, social e institucional pelo reconhecimento e valorização da profissão de educadores, habilitados em cursos de Pedagogia e nas licenciaturas. Ademais, as reformas da Previdência e Trabalhista, em curso no Congresso, 
neste ano, ampliam o ataque aos direitos dos trabalhadores em educação e às suas organizações sindicais.

Diante da concepção do ajuste fiscal em curso, o eixo central da reforma do ensino médio - para além do ataque à profissionalização do magistério e ao currículo universal voltado à formação integral dos estudantes - está na privatização da etapa final da educação básica. A lei permite que os sistemas públicos firmem parcerias, inclusive na modalidade a distância, com a iniciativa privada para a oferta da parte diversificada do currículo, em especial na modalidade de educação técnica-profissional. Diante dessa perspectiva, o Estado concentrará sua obrigatoriedade de oferta escolar aos conteúdos da Base Nacional Comum Curricular (BNCC), podendo delegar aos empresários o restante da formação, também por meio de repasses de verbas públicas para as escolas privadas, subordinando novamente a educação brasileira aos ditames das agências multilaterais, como o FMI e o Banco Mundial.

Outro significativo vetor de recursos públicos para a iniciativa privada foi criado com a alteração do Decreto-Lei 236/67. Trata-se da deferência que a Lei n. 13.415 fez ao lobby das emissoras de televisão que poderão celebrar convênios com o MEC para transmitir "programas relativos à educação básica, profissional, tecnológica, superior e a outras matérias de interesse da educação". E isso consiste em disseminar a cultura dos Telecursos, de qualidade e eficiência mais que duvidosos, para todos os níveis, etapas e modalidades da educação, com alto financiamento público.

Em síntese, o conteúdo e a organização da reforma do ensino médio seguem a lógica do mercado, sob a égide das agências multilaterais, conduzidas pelo Consenso de Washington, além de reduzir a formação geral dos estudantes e fragmentar o conceito de educação básica, pois os conteúdos curriculares não serão os mesmos para todos, estando, inclusive, os discentes das redes públicas em situação de desvantagem em relação aos da rede privada, que poderão manter outras disciplinas em seus currículos.

Já a forma apressada com se aprovou mais esse expediente neoliberal foi ainda pior que a empregada em outras propostas do governo, pois se pautou numa Medida Provisória (MP). Não há como deixar de questionar esse expediente autoritário, que inviabiliza o amplo e necessário debate social sobre tema da mais alta relevância para a sociedade.

Tal como aconteceu com a Emenda Constitucional n. 95 - que estabeleceu ajuste fiscal de 20 anos sobre as despesas correntes da União, congelando os investimentos nas áreas sociais, a remuneração dos servidores públicos, e desvinculando os recursos constitucionais para a educação e a saúde -, o objetivo da celeridade na reforma do ensino médio não foi outro senão evitar a reação das classes populares - as principais atingidas pelas reformas -, que continuam entorpecidas por parcela da grande mídia, que apoia o golpe e estimula a descrença na política e o pseudo combate à corrupção.

A CNTE e seus cinquenta sindicatos filiados em todo o País repudiaram durante o processo parlamentar a forma autoritária e o conteúdo extemporâneo da reforma do 
ensino médio, que investiu na dicotomia entre áreas de conhecimento geral e específico e limitou a capacidade de pensar da juventude. E essa contestação será mantida agora na fase de implementação nos estados.

Dada a associação da reforma do ensino médio às medidas de ajuste fiscal, a mobilização da Confederação e de seus sindicatos filiados será de combater a reforma do ensino médio em conjunto com outras medidas, a exemplo do ajuste fiscal (EC n. 95) e da Lei 13.439, que ampliou a terceirização para todas as áreas, inclusive no serviço público, já existindo diploma legal para terceirizar as escolas e seus profissionais por meio de Organizações Sociais, através da Lei n. 9.637/1998.

As ações da CNTE e de entidades parceiras na luta contra a reforma do ensino médio - e contra a imposição do projeto neoliberal derrotado nas urnas - têm sido as mais diversas, com foco na conscientização das categorias de trabalhadores e no enfrentamento das pautas reacionárias nas ruas, no Congresso e no Poder Judiciário.

A CNTE ingressou com ação direta de inconstitucionalidade no STF contra a MP n. 746, transformada em Lei 13.415. A entidade também enviou cartazes e jornais murais denunciando as reformas educacional, previdenciária e trabalhista. $\mathrm{O}$ engajamento dos trabalhadores em educação tem sido decisivo na convocação das Greves Gerais de 2017 pelas Centrais Sindicais, tendo a CNTE convocado a primeira greve de âmbito nacional em 15 de março de 2017 contra o processo de desmonte do Estado promovido pelo governo golpista, e a reforma do ensino médio está na pauta de mobilização.

Ao contrário do apartheid socio-educacional que a reforma do ensino médio pretende instalar no Brasil, a luta da CNTE é por escola pública, gratuita, democrática, laica e de qualidade, socialmente referenciada para todos e todas.

Abaixo, destacamos alguns pontos da reforma do ensino médio, aprovada na forma da Lei n. 13.415:

A Lei prevê até 1.800 horas para os conteúdos da BNCC (42,9\% do currículo total do ensino médio em tempo integral), e as escolas não são obrigadas a ofertar todas as áreas específicas do currículo (os outros 57,1\%). Pior: o estudante de determinado município que não se sentir contemplado com a(s) área(s) específica(s) ofertada(s) em sua escola, terá que cursar outra área diferente da predileta ou mudar de cidade ou pagar um curso na rede privada. Com isso, é mitigado o próprio direito à educação, aumentando as desigualdades socio-educacionais.

As redes públicas terão prazo de cinco anos para implementar a jornada mínima de 1.000 horas anuais no ensino médio de tempo integral, a contar da publicação da BNCC, ainda em discussão no Conselho Nacional de Educação neste ano.

A ajuda financeira da União aos estados, com duração máxima de 10 anos, não está assegurada e ficará (sempre) condicionada à disponibilidade orçamentária do MEC. Ou seja, a tão propalada ajuda federal às escolas de ensino médio integral rebaixa de imediato a política dos governos Lula e Dilma, pois não é universal. Ao contrário, parece 
mais um projeto piloto, na medida que poderá manter as cerca de 500 mil matrículas como referência (cerca de $6 \%$ do total das matrículas), desde que haja recursos suficientes. Isso elucida a vinculação da reforma com a EC n. 95, pois o que está verdadeiramente em jogo é o ajuste fiscal.

A reforma instituiu o foco na aprendizagem de Matemática e Português e manteve, após muita polêmica, a obrigatoriedade das disciplinas de Artes e Educação Física em toda a educação básica. Porém, o mesmo não ocorreu com as disciplinas de Filosofia e a Sociologia, embora a CNTE entenda que a redação ao inciso IV do novo art. 35-A, que redefine as nomenclaturas e terminologias das áreas de conhecimento que deverão compor a Base Nacional Comum Curricular, tornou os conteúdos dessas duas matérias obrigatórios na formulação da BNCC.

Como dito acima, além de flexibilizar a formação do magistério por "notório saber", a Lei 13.415 incluiu uma nova categoria de profissionais da educação, que são os profissionais graduados em diversas áreas que não o magistério, mas que tenham feito a complementação pedagógica, conforme disposto pelo Conselho Nacional de Educação. Trata-se, temerosamente, de ação que visa legalizar a precariedade da formação docente, algo que contraria todo o esforço da sociedade em valorizar a profissão do magistério e dos profissionais da educação, inclusive sob o aspecto da sólida formação profissional, indispensável para a qualidade da educação escolar.

Em 13 de junho de 2017, o Ministério da Educação publicou a Portaria n. 727, estabelecendo "novas diretrizes, novos parâmetros e critérios para o Programa de Fomento às Escolas de Ensino Médio em Tempo Integral (EMTI), em conformidade com a Lei 13.415, de 16 de fevereiro de 2017".

Não obstante as considerações gerais da Portaria 727 se aterem às ações conjuntas entre os entes federados, na meta 3 do PNE (Lei 13.005) e na necessidade de ampliação do ensino médio em tempo integral, as ações dispostas na normativa em apreço não preveem a regulamentação dos regimes de colaboração e cooperação entre os entes federados (art. 13 e estratégia 20.9 do PNE) e tampouco asseguram o cumprimento das metas de inclusão da juventude no ensino médio, em especial na forma de educação integral.

Segue a avaliação inicial da CNTE sobre a Portaria/MEC n. 727:

1. A implantação da educação em tempo integral no ensino médio pode significar a exclusão de outros jovens e adultos matriculados em EJA, pois as escolas que ofertam essa modalidade de educação terão que ofertar exclusivamente o ensino médio;

2. Atualmente, conforme planilha disponibilizada no anexo II da Portaria 727, apenas 572 escolas que abrangem 257.400 matrículas estão aptas a ingressar no programa federal de fomento ao ensino médio de tempo integral. 
3. Com base na informação do item anterior, muito provavelmente ter-se-á uma redução nas matrículas de ensino médio em tempo integral entre os anos de 2016 e 2018, quando está prevista a instituição do programa (EMTI). Em 2016 havia 518.702 matrículas em tempo integral no ensino médio público, e, para 2018, está sendo projetado o atendimento mínimo de 257.400, uma redução de quase $50 \%$ !

4. Esse gigantesco retrocesso nas matrículas em tempo integral deverá ocorrer por duas razões: i) o art. 28 reafirma que os recursos federais somente serão repassados caso haja disponibilidade orçamentária do MEC e desde que as escolas e os sistemas cumpram os requisitos de elegibilidade (sendo que apenas 572 atendem as especificações do Programa Federal); e ii) o art. 30 diz que as escolas partícipes de programas anteriores deverão se enquadrar nos critérios da atual Portaria. Caso não estejam aptas, serão descredenciadas.

5. A adesão dos entes federados ao EMTI estará condicionada à assinatura de Termo de Compromisso específico, disposto no anexo I da Portaria, podendo ser rescindido unilateralmente pela União, por inúmeras razões, durante o período de gestão.

6. Principais critérios para elegibilidade das escolas no EMTI: i) mínimo de 120 estudantes no primeiro ano do ensino médio; ii) localizada em regiões de alta vulnerabilidade social; iii) existência de ao menos 4 dos 6 itens de infraestrutura exigidos no anexo III (biblioteca ou sala de leitura de 50 $\mathrm{m}^{2}, 8$ salas de aula com no mínimo $40 \mathrm{~m}^{2}$, quadra poliesportiva de $400 \mathrm{~m}^{2}$, vestiário masculino e feminino de $16 \mathrm{~m}^{2}$ cada, cozinha de $30 \mathrm{~m}^{2}$ e refeitório); escolas onde mais da metade dos estudantes tenham menos de 7 horas de aula/dia.

7. Não ser participante do programa. As escolas partícipes de programas similares terão que passar por processo de avaliação previsto no capítulo VII da Portaria 727, para fins de enquadramento (ou não) no EMTI.

A Portaria/MEC 727 é a prova cabal da propaganda enganosa que permeou o processo de aprovação da Lei 13.415, levando grande parte dos jovens brasileiros a acreditar que teria um ensino médio inovador, para todos/as. A proposta do MEC, traduzida no EMTI, embora vise priorizar áreas de vulnerabilidade socioeconômica, restringe as matrículas, deixando a maioria dos estudantes desamparada ou à mercê dos contratos que os estados passarão a firmar com a iniciativa privada para a oferta das áreas específicas do currículo. 
A CNTE atuará fortemente contra a implementação dessa política de desresponsabilização do Estado perante o ensino médio público, uma vez que os sistemas de ensino não são obrigados a aderie a ela. E o trabalho de conscientização da sociedade é o primeiro passo para reverter esse processo de extrema gravidade, que rompeu com a indissociabilidade da educação básica e estimulou a privatização da escola pública, fomentado ainda a desprofissionalização e a terceirização dos/as trabalhadores/as em educação. 